\title{
Franklin Institute.
}

[Proceedings of the Stated Meeting, held Wednesday, November 17, 1886.].

Hall of the Institute, November 17, I 886.

Vice-President Chas. Bullock, in the Chair.

Present, 109 members and eleven visitors.

Additions to membership since the previous meeting, eight.

By direction of the Chairman of the Committee on Science and the Arts, the Secretary reported the Committee's recommendation for the award of the Elliot Cresson Medal to Robert H. RamSEy, of Philadelphia, for his "CarTransfer System and Apparatus ;" and to Thaddeus S. C. Lowe, of Norristown, Pa., for his "Improvements in the Manufacture and Applications of Water-Gas for Heating and Lighting."

The recommendations were severally approved, and the Secretary was directed to take the usual measures to carry them into effect.

A report of progress was presented on behalf of the Special Committees. having in charge (I.) the preparation of a plan for a "State Weather Service," and (2.) the consideration of Mr. Paul La Cour's protest against the award of the Elliot Cresson Medal to Patrick B. Delany.

Mr. FRED'K E. IVEs, of Philadelphia, presented a preliminary communication on the "Application of Phosphorescent Substances to Photography." An abstract of this communication appears in this impression of the JOURNAL.

The Secretary's report embraced remarks on the "Future Water-Supply of Philadelphia," on the "Progress of the East-Side Connecting Railway," and on some of the "Indirect Advantages of Natural Gas."

Adjourned.

WM. H. WAHL, Secretary.

Druidical Remains in Peru.-M. Daubrée offers, in the name of $M$. Habich, Director of the School of Civil Constructions and Mines, of Lima, thefifth volume of Anales de Construcciones Ciziles $y$ de Minas. An article by M. Chalon, on "The Buildings of Ancient Peru," is worthy of notice and of universal interest. To the primitive epoch, succeeding the pre-historic, belong constructions laid with rough blocks, sometimes of very great dimension. It is very remarkable that these monuments offer the greatest resemblance to. those which are known in the old world, particularly in France, under the names of raised stones, menhirs, cromlechs, dolmens and the general term druidical. They are very numerous and are spread through all parts of the territory of Peru. According to the author, they appear to have a religinus. significance and to have served for sepulchre and sacrifice.-Comples Rendus, . May 24, 1886 . 